\title{
VARIABILITATEA ŞI HERITABILITATEA VIGORII BOABELOR DE GRÂU COMUN LA INTERACŢIUNEA CU DRECHSLERA SOROKINIANA
}

\author{
Lupaşcu G., Gavzer S. \\ Institutul de Genetică, Fiziologie şi Protecţie a Plantelor, \\ Chişinău, Republica Moldova, galinalupascu51@gmail.com
}

Abstract:The article presents data on the effects of the interaction of common wheat with the fungus Drechslera sorokiniana on grain vigor. Its differentiated action on germination and seedling length (LP) was found. The vigor index (VI) depended more on LP $(r=0.90 *)$ than on the germination 
level $(\mathrm{r}=0.52 *, \mathrm{p} \leq 0.05)$. The coefficient of heritability in the broad sense (h2) was $71.3 \%$ for LP and $60.1 \%$ - for VI. The association of h2 and genetic progress with high values reveals the pronounced contribution of additive genetic variance in the control of the vigor index, which offers increased opportunities in the selection of wheat plants resistant to this pathogen in restricted terms.

Key words: wheat, fungus, Drechslera sorokiniana, germination, plant length, seed vigour, variance, heritability.

\section{Introducere}

Calitatea seminței - o componentă importantă a industriei agricole și, totodată, fundamentul succesului programelor de producere a culturilor, este determinată de diferiți factori, inclusiv de vigoarea acesteia - însușire care conferă o capacitate inerentă creșterii în condiții favorabile și nefavorabile [6].

Aprecierea vigorii semințelor în calitate de monitoring de bază al potențialului fiziologic al semințelor și suport al strategiilor de decize pentru selectarea loturilor de semințe de calitate înaltă, prezintă un aport benefic important pentru industria semințelor. Potențialele atribute ale vigorii semințelor în calitate de caracter fiziologic fundamental și asocierea lor cu "field stand establishment" și productivitatea culturii au fost recunoscute în întreaga lume încă din anul 1960. Emergența rapidă și uniformă a plantulelor viguroase este un eveniment-cheie pentru asigurarea unei performanțe înalte a plantelor în ceea ce privește uniformitatea dezvoltării, roada și calitatea roadei [4]. Germinația și vigoarea plantulelor (germinație, \% x lungimea plantulei, cm) sunt doi parametri care definesc calitatea semințelor [8]. Testul "vigoarea seminţelor/plantulelor" a fost utilizat cu succes în cele mai diferite scopuri: stabilirea influenței gărgăriței asupra calității semințelor de sorg după păstrare îndelungată [8], variabilității genotipice a muștarului (Brassica juncea (L.) [6], influenței unor metale grele ( $\mathrm{Cd}, \mathrm{Pb}, \mathrm{Zn}, \mathrm{Ni})$ asupra germinației și creșterii plantulelor de floarea-soarelui [9], impactului patogenilor Fusarium spp. asupra semințelor de grâu și ovăz [5]. Ca rezultat, s-a constatat că toți acești factori - biotici și abiotici au determinat în mare măsură calitatea seminţelor.

Putregaiul de rădăcină la grâul comun de toamnă (Triticum aestivum L.) este una din cele mai răspândite maladii în zonele de cultivare a acestuia. În condițiile Republicii Moldova, putregaiul de rădăcină la grâul comun de toamnă este cauzat de o multitudine de specii fungice, printre care Drechslera sorokiniana se izolează din plantele cu semne de putrefacție pe durata întregii vegetaţii și se remarcă prin incidență și virulență sporită [7].

Scopul cercetărilor a constat în identificarea influenței fungului D. sorokiniana asupra variabilităţii şi heritabilităţii vigorii boabelor de grâu comun.

\section{Material și metode}

Cercetările au fost efectuate în condiţii de laborator. În calitate de material au fost utilizate 8 genotipuri de grâu comun de toamnă ce prezintă linii şi soiuri cu indici înalţi de productivitate - L 1/3/M 3, L Sel./Accent, L Bas./M 30, L M/M3, L Cub. 101/Bas., Moldova 16, Moldova 66, Moldova 11.

Tulpinile fungului Drechslera sorokiniana au fost izolate din plante de grâu cu semne de putrefacţie la baza tulpinii, pe mediu nutritiv Potato Dextrose Agar, şi identificate în baza caracterelor morfologo-culturale şi microscopice [3] (Fig.1). 


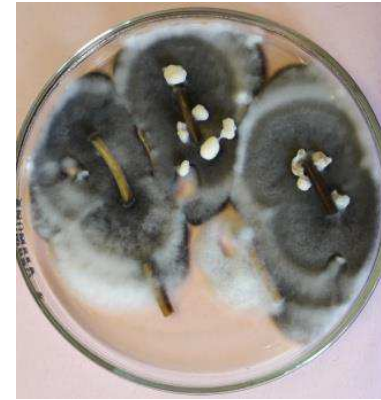

A

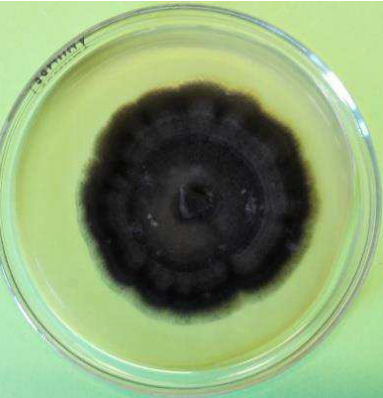

B

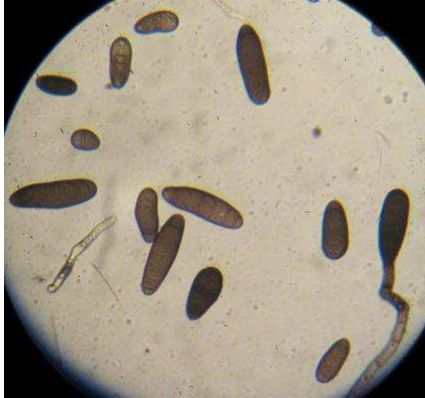

$\mathrm{C}$

Fig. 1. Izolarea tulpinilor din plante bolnave de grâu (A), colonie (B), conidii (C) de D. sorokiniana

Filtratele de cultură (FC) ale fungului s-au preparat în baza mediului lichid Cszapek, numerotate FC 1, FC 2, FC 3. Boabele de grâu au fost tratate cu FC timp de 18 ore, după care au fost clătite cu apă distilată şi menţinute timp de 6 zile în cutii Petri pe hârtie de filtru umectată. În calitate de caractere metrice au servit germinaţia (\%) şi lungimea plantulelor (cm) care sunt asociate cu adaptarea la stresul biotic la etape timpurii ale ontogenezei plantelor.

S-au calculat: varianța genotipică $\left(\sigma_{\mathrm{g}}^{2}\right)$, varianța fenotipică $\left(\sigma_{\mathrm{ph}}^{2}\right)$, coeficientul de heritabilitate în sens larg $\left(h^{2}\right)$, coeficientul de variație fenotipic (PCV), coeficientul de variație genotipic (GCV), GAM (\%) - avantajul genetic pentru diferențialul de selecție 2,06 la presiunea de selecție de $5 \%[1,2]$. Datele au fost prelucrate în pachetul de soft STATISTICA 8.

\section{Rezultate şi discuţii}

S-a constatat că tratarea boabelor de grâu cu FC ale fungului $D$. sorokiniana nu a avut efecte semnificative asupra capacității de germinare, însă a influenţat în mod diferit lungimea plantulei şi indicele de vigoare (tab. 1).

Prin analiză corelaţională, s-a constatat că indicele de vigoare a depins mai mult de lungimea plantulei $\left(r=0,90^{*}\right)$ decât de facultatea germinativă $\left(r=0,52^{*}, p<0,05\right)$.

Tabelul 1. Influenţa fungului $D$. sorokiniana asupra vigorii boabelor de grâu

\begin{tabular}{|c|c|c|c|c|c|c|c|c|}
\hline $\mathrm{Nr}$ & Genotip & $\begin{array}{l}\text { Vari } \\
\text {-antă }\end{array}$ & $\begin{array}{c}\text { Germinaţi } \\
\text { e } \%\end{array}$ & $\begin{array}{c}\text { Raport } \\
\text { la } \\
\text { martor } \\
, \%\end{array}$ & $\begin{array}{l}\text { Lungimea } \\
\text { plantulei, } \\
\mathrm{cm}\end{array}$ & $\begin{array}{c}\text { Raport } \\
\text { la } \\
\text { martor } \\
, \%\end{array}$ & $\begin{array}{ll}\text { Indice } & \text { de } \\
\text { vigoare } & \end{array}$ & $\begin{array}{c}\text { Raport } \\
\text { la } \\
\text { martor } \\
, \%\end{array}$ \\
\hline 1 & \multirow{4}{*}{$\begin{array}{c}\mathrm{L} \\
1 / 3 / \mathrm{M} 3 \\
0\end{array}$} & $\mathrm{M}$ & $82,5 \pm 1,4$ & - & $13,77 \pm 1,48$ & - & $1214,0 \pm 138,7$ & - \\
\hline 2 & & FC1 & $82,5 \pm 4,3$ & 100,0 & $14,03 \pm 0,49$ & 101,9 & $1162,0 \pm 101,4$ & 95,7 \\
\hline 3 & & $\mathrm{FC} 2$ & $75,8 \pm 6,0$ & 91,9 & $13,07 \pm 0,73$ & 94,9 & $982,3 \pm 25,8$ & 80,9 \\
\hline 4 & & FC3 & $80,0 \pm 3,8$ & 97,0 & $12,60 \pm 0,21$ & 91,5 & $1008,9 \pm 60,0$ & 83,1 \\
\hline 5 & \multirow{4}{*}{$\begin{array}{l}\text { L Sel./ } \\
\text { Accent }\end{array}$} & $\mathrm{M}$ & $81,7 \pm 0,8$ & - & $16,67 \pm 0,38$ & - & $1369,2 \pm 33,5$ & - \\
\hline 6 & & $\mathrm{FC} 1$ & $82,5 \pm 6,6$ & 101,0 & $15,20 \pm 0,40$ & 90,6 & $1248,7 \pm 69,3$ & 91,2 \\
\hline 7 & & FC2 & $80,0 \pm 6,3$ & 98,0 & $\begin{array}{c}13,77 \pm 0,74 \\
*\end{array}$ & 82,1 & $1092,2 \pm 27,1 *$ & 79,8 \\
\hline 8 & & FC3 & $77,5 \pm 7,5$ & 94,9 & $\begin{array}{c}11,53 \pm 0,64 \\
*\end{array}$ & 68,8 & $894,8 \pm 106,0 *$ & 65,4 \\
\hline 9 & \multirow{2}{*}{$\begin{array}{c}\text { L Bas./ } \\
\text { M } 30\end{array}$} & $M$ & $82,5 \pm 1,4$ & - & $16,10 \pm 1,66$ & - & $1325,2 \pm 126,4$ & - \\
\hline 10 & & FC1 & $82,5 \pm 1,4$ & 100,0 & $16,90 \pm 0,25$ & 105,0 & $1393,7 \pm 14,7$ & 105,2 \\
\hline
\end{tabular}




\begin{tabular}{|c|c|c|c|c|c|c|c|c|}
\hline 11 & & $\mathrm{FC} 2$ & $76,7 \pm 6,8$ & 92,9 & $13,03 \pm 1,28$ & 80,9 & $1008,9 \pm 161,0$ & 76,1 \\
\hline 12 & & FC3 & $81,7 \pm 4,2$ & 99,0 & $\begin{array}{c}11,90 \pm 0,53 \\
*\end{array}$ & 73,9 & $971,0 \pm 57,5 *$ & 73,3 \\
\hline 13 & \multirow{4}{*}{$\begin{array}{c}\mathrm{L} \\
\mathrm{M} / \mathrm{M} 30\end{array}$} & $\mathrm{M}$ & $80,8 \pm 4,6$ & - & $14,57 \pm 0,73$ & - & $1170,8 \pm 11,8$ & - \\
\hline 14 & & $\mathrm{FC} 1$ & $82,5 \pm 2,5$ & 102,1 & $16,90 \pm 0,10$ & 116,0 & $1394,7 \pm 50,7^{*}$ & 119,1 \\
\hline 15 & & $\mathrm{FC} 2$ & $83,3 \pm 2,2$ & 103,1 & $13,97 \pm 0,72$ & 95,9 & $1160,7 \pm 30,4$ & 99,1 \\
\hline 16 & & FC3 & $80,8 \pm 3,6$ & 100,0 & $14,23 \pm 0,15$ & 97,7 & $1150,8 \pm 55,8$ & 98,3 \\
\hline 17 & \multirow{4}{*}{$\begin{array}{c}\text { L Cub. } \\
\text { 101/Bas } \\
.\end{array}$} & $\mathrm{M}$ & $80,8 \pm 3,0$ & - & $20,23 \pm 0,37$ & - & $1634,0 \pm 46,1$ & - \\
\hline 18 & & $\mathrm{FC1}$ & $82,3 \pm 1,5$ & 101,9 & $18,10 \pm 0,29$ & 89,5 & $1497,7 \pm 15,4$ & 91,7 \\
\hline 19 & & FC2 & $80,8 \pm 5,5$ & 100,0 & $\begin{array}{c}14,97 \pm 0,63 \\
*\end{array}$ & 74,0 & $1215,2 \pm 124,9$ & 74,4 \\
\hline 20 & & FC3 & $83,3 \pm 3,0$ & 103,1 & $\begin{array}{c}14,70 \pm 0,46 \\
*\end{array}$ & 72,7 & $1227,5 \pm 79,1$ & 75,1 \\
\hline 21 & \multirow[t]{4}{*}{ M 16} & $\mathrm{M}$ & $83,3 \pm 0,8$ & - & $16,53 \pm 1,48$ & - & $1378,7 \pm 128,4$ & - \\
\hline 22 & & FC1 & $87,5 \pm 2,9$ & 105,0 & $16,27 \pm 0,38$ & 98,4 & $1424,6 \pm 74,9$ & 103,3 \\
\hline 23 & & $\mathrm{FC} 2$ & $83,3 \pm 0,8$ & 100,0 & $15,23 \pm 0,41$ & 92,1 & $1270,0 \pm 45,0 *$ & 92,1 \\
\hline 24 & & FC3 & $81,7 \pm 5,8$ & 98,0 & $14,80 \pm 0,38$ & 89,5 & $\begin{array}{c}1210,7 \pm 103,3 \\
*\end{array}$ & 87,8 \\
\hline 25 & \multirow[t]{4}{*}{ M 66} & $\mathrm{M}$ & $83,3 \pm 1,7$ & - & $16,73 \pm 0,32$ & - & $1394,3 \pm 69,6$ & - \\
\hline 26 & & $\mathrm{FC} 1$ & $80,0 \pm 5,8$ & 96,0 & $16,30 \pm 0,27$ & 97,4 & $1307,0 \pm 114,6$ & 93,7 \\
\hline 27 & & $\mathrm{FC} 2$ & $78,3 \pm 3,6$ & 94,0 & $12,07 \pm 1,50$ & 72,2 & $950,0 \pm 137,0$ & 68,1 \\
\hline 28 & & FC3 & $82,5 \pm 2,5$ & 99,0 & $13,87 \pm 0,09$ & 82,9 & $1143,9 \pm 34,2$ & 82,0 \\
\hline 29 & \multirow[t]{4}{*}{ M 11} & $\mathrm{M}$ & $84,0 \pm 2,1$ & - & $16,73 \pm 0,58$ & - & $1406,1 \pm 65,2$ & - \\
\hline 30 & & FC1 & $81,7 \pm 1,7$ & 97,2 & $16,73 \pm 0,52$ & 100,0 & $1365,0 \pm 21,5$ & 97,1 \\
\hline 31 & & $\mathrm{FC} 2$ & $80,8 \pm 4,2$ & 96,2 & $14,27 \pm 0,58$ & 85,3 & $1157,2 \pm 100,2$ & 82,3 \\
\hline 32 & & FC3 & $85,0 \pm 2,9$ & 101,2 & $\begin{array}{c}12,83 \pm 0,60 \\
*\end{array}$ & 76,7 & $1090,0 \pm 55,1^{*}$ & 77,5 \\
\hline
\end{tabular}

*- diferenţă cu suport statistic de martor, $\mathrm{p} \leq 0,05$.

Analiza factorială a demonstrat că în reacția genotipurilor de grâu la tulpinile de $D$. sorokiniana, rolul factorului de izolată a predominat în sursa de variaţie a lungimii plantulei și indicelui de vigoare $-64,4-78,0 \%$ (Tab. 2).

Tabelul 2. Analiza factorială a influenței interacțiunilor grâu x D. sorokiniana asupra organelor de creștere şi dezvoltare

\begin{tabular}{|c|c|c|c|c|c|c|}
\hline \multirow[t]{2}{*}{ Sursă de variație } & \multirow{2}{*}{$\begin{array}{l}\text { Grade } \\
\text { de } \\
\text { liberta- } \\
\text { te }\end{array}$} & \multicolumn{2}{|c|}{ Lungimea plantulei } & \multirow{2}{*}{$\begin{array}{c}\text { Grade } \\
\text { de } \\
\text { libertate }\end{array}$} & \multicolumn{2}{|c|}{ Indice de vigoare } \\
\hline & & $\begin{array}{l}\text { Suma } \\
\text { medie a } \\
\text { pătratelor }\end{array}$ & $\begin{array}{l}\text { Ponderea } \\
\text { sursei de } \\
\text { variație, \% }\end{array}$ & & $\begin{array}{l}\text { Suma } \\
\text { medie a } \\
\text { pătratelor }\end{array}$ & $\begin{array}{l}\text { Ponderea } \\
\text { sursei de } \\
\text { variatie, } \\
\%\end{array}$ \\
\hline Genotip & 7 & 13,69 & 16,50 & 7 & 111324 & 16,06 \\
\hline $\begin{array}{ll}\begin{array}{l}\text { Izolată } \\
\text { sorokiniana }\end{array} & D . \\
\end{array}$ & 3 & 64,39 & 77,60 & 3 & 540373 & 77,96 \\
\hline Genotip x izolată & 21 & 3,28 & 3,95 & 21 & 21260 & 3,07 \\
\hline Efecte aleatorii & 64 & 1,62 & 1,95 & 64 & 20180 & 2,91 \\
\hline
\end{tabular}

$*_{-} \mathrm{p}<0,05$. 
S-a constatat că varianţa fenotipică $\left(\sigma_{p}^{2}\right)$ a fost mult mai înaltă decât varianța genotipică $\left(\sigma_{\mathrm{g}}^{2}\right)$ în cazul indicelui de vigoare $(+66,4 \%)$ decât a lungimii plantulei $(+40,3 \%)$ (tab. 3).

Tabelul 3. Variabilitatea genetică a genotipurilor de grâu în reacția la $D$. sorokiniana

\begin{tabular}{|l|c|c|}
\hline \multicolumn{1}{|c|}{ Parametru } & Lungimea plantulei & Indice de vigoare \\
\hline$\sigma^{2}{ }_{\mathrm{G}}$ & 4,02 & 30381,3 \\
\hline$\sigma^{2} \mathrm{P}$ & 5,64 & 50561,3 \\
\hline $\mathrm{h}^{2}, \%$ & 71,3 & 60,1 \\
\hline $\mathrm{GCV}, \%$ & 13,40 & 14,22 \\
\hline $\mathrm{PCV}, \%$ & 15,88 & 18,35 \\
\hline PCV - GCV, \% & 2,48 & 4,13 \\
\hline GA & 3,25 & 258,4 \\
\hline GAM, $\%$ & 21,7 & 21,08 \\
\hline
\end{tabular}

Coeficientul de heritabilitate în sens larg a constituit în cazul lungimii plantulei $71,3 \%$, iar a indicelui de vigoare - 60,1\%. Asocierea coeficientului de heritabilitate și progresului genetic cu valori relativ înalte $(21,1-21,7 \%)$ relevă contribuția pronunțată a varianței genetice aditive în controlul lungimii plantulei şi indicelui de vigoare, ceea ce prezintă oportunităţi sporite în selecția plantelor de grâu rezistente la acest patogen în termeni restrânşi.

\section{Concluzii}

1. Interacţiunea grâului comun de toamnă cu patogenul fungic din sol D. sorokiniana are un impact direct asupra unuia din indicii de bază ai calităţii - vigoarea boabelor.

2. Reacţia diferenţiată a liniilor şi soiurilor de grâu la filtratele de cultură $D$. sorokiniana relevă variabilitatea acestora. Varianţa fenotipică a fost mult mai înaltă decât varianța genotipică în cazul indicelui de vigoare $(+66,4 \%)$ decât a lungimii plantulei $(+40,3 \%)$.

3. Coeficientul de heritabilitate în sens larg a constituit în cazul lungimii plantulei $71,3 \%$, a indicelui de vigoare $-60,1 \%$, iar progresului genetic a înregistrat $21,1-21,7 \%$, ceea ce denotă şanse reale de ameliorare a rezistenţei grâului la patogen prin selectări individuale.

\section{Bibliografie}

1. Adeniji O.T. Genetic variation and heritability for foliage yield and yield component traits in edible Amaranthus cruentus [L.] genotypes. In: Bangladesh J. Agril. Res. 2018, 43(3), p. 513-524.

2. Balkan A. Genetic variability, heritability and genetic advance for yield and quality traits in M2-4 generations of bread wheat (Triticum aestivum L.) genotypes. In: Turkish J. of Field Crops. 2018, 2, p. 173-179.

3. Barnett H.L., Hunter B.B. Illustrated Genera of Imperfect Fungi, Fourth Edition. APS Press, 1998, 218 pp.

4. Filho J.M. Seed vigor testing: an overview of the past, present and future perspective. In: Sci. agric. (Piracicaba, Braz.), 2015, vol.72, no.4, 5. https://doi.org/10.1590/0103-90162015-0007

5. Hassani F., Zare L., Khaledi N. Evaluation of germination and vigor indices associated with Fusarium-infected seeds in pre-basic seeds wheat fields. In: Journal of Plant Protection Research, 2019, 59(1), p. 69-85. 
6. Himanshu R. et al. Seed Vigour Assessment in Different Varieties of Indian mustard (Brassica juncea (L.) Czern. \& Coss.). In: Int. J. Curr. Microbiol. App. Sci, 2017, 6(10), p. 1930-1936

7. Lupașcu G., Gavzer S. Diversitatea agenților cauzali ai maladiilor de rădăcină la grâul comun (Triticum aestivum L.). In: Conf. Şt. Int."Protecţia Plantelor în Agricultura Convenţională şi Ecologică", 10-12 decembrie 2018, Chişinău. Chişinău: Biotehdesign, 2018, p. 32-36.

8. Pradeep. Seed quality parameters (Germination percentage and seedling vigor index) of rabi sorghum seeds influenced by tice weevil infestation. In: MOJ Toxicol., 2018, 4, p.

9. Zhao X. et al. Estimation of the Seedling Vigor Index of Sunflowers Treated with Various Heavy Metals. In: J. Bioremed. Biodeg., 2016, 7: 353. doi:10.4172/21556199.1000353 